\title{
Efeito de tipos de leite sobre oídio em abóbora plantadas a campo
}

\author{
Mariana Zatarim $^{1}$; Antonio Ismael I. Cardoso ${ }^{2}$; Edson Luiz Furtado ${ }^{2}$ \\ ${ }^{1}$ IDATERRA, C. Postal 472, 79031-902 Campo Grande-MS; ${ }^{2}$ UNESP-FCA, Depto Produção Vegetal, C. Postal 237, $18603-970$ \\ Botucatu-SP; E-mail:zmariana@ig.com.br
}

\section{RESUMO}

O trabalho foi realizado a campo para avaliar a eficiência de diversos tipos de leite de vaca sobre o oídio da abóbora cultivar Piramoita, causado por Sphaerotheca fuliginea. Utilizou-se o delineamento experimental de blocos ao acaso com seis tratamentos, cinco repetições e cinco plantas por parcela. Os tratamentos foram: leite cru, leite pasteurizado do tipo $\mathrm{C}$, leite integral do tipo longa vida, leite pasteurizado tipo $\mathrm{C}+$ Yakult $^{\circledR}$, leite integral do tipo longa vida + Yakult $^{\circledast}$ e água como controle. Os melhores resultados no controle da doença foram obtidos com leite de vaca cru, com leite do tipo $\mathrm{C}$ e leite do tipo $\mathrm{C}+$ Yakult $^{\circledR}$. Concluiu-se que leite é uma alternativa viável no controle do oídio, mesmo após o início da infecção, no campo. Sua utilização na forma de leite cru mais eficiente e na forma de longa vida o menos eficiente.

Palavras-chave: Cucurbita moschata L., Sphaerotheca fuliginea, produto lácteo fermentado, doença.

\begin{abstract}
Effect of types of cow milk on the powdery mildew control of pumpkin under field conditions
\end{abstract}

In the present work we evaluated, under field conditions, the efficiency of several types of cow milk on the control of powdery mildew of pumpkin cv. Piramoita, caused by Sphaerotheca fuliginea. The experimental design consisted of randomized blocks with six treatments, five replications and five plants per plot. The treatments were: raw cow milk, pasteurized type $\mathrm{C}$ milk, integral long life milk and the association of the last two with Yakult ${ }^{\circledR}$ and a control with water. Milk is a viable alternative to control powdery mildew, even after infections have started under field conditions. Raw cow milk, type $\mathrm{C}$ milk and type $\mathrm{C}+$ Yakult $^{\circledR}$ were the most efficient and integral long life was the least efficient.

Keywords: Cucurbita moschata L., Sphaerotheca fuliginea, lacteous fermented product, disease.

\section{(Recebido para publicação em 22 de dezembro de 2003 e aceito em 8 de dezembro de 2004)}

$\mathrm{O}$ oídio é uma doença fúngica causada por Sphaerotheca fuliginea, de ocorrência universal, considerada uma das mais comuns entre as cucurbitáceas cultivadas e selvagens. Todas são suscetíveis, contudo a severidade está condicionada ao clima, à espécie e à cultivar. O fungo pode atacar toda parte aérea da planta, sendo as folhas as mais afetadas. Os sintomas da doença caracterizam-se pela presença de uma eflorescência branca pulverulenta, formada por micélio, conidióforos e conídios do patógeno, podendo ocorrer em todos os tecidos das folhas, hastes e pecíolos. No início da patogênese, áreas restritas na superfície abaxial das folhas são colonizadas, mas gradualmente a superfície adaxial também é colonizada. Os primeiros sinais são mais evidentes com o surgimento de manchas amareladas nas folhas, evoluindo para marrom até secarem completamente. Em alguns casos toda a folhagem é necrosada levando a planta à morte. Nesses casos, a produção pode ser seriamente comprometida (KIMATI et al., 1980; BERNHARDT et al., 1988; ZIV; ZITTER, 1992; BEDENDO, 1995; KUROZAWA; PAVAN, 1997; BETTIOL; ASTIARRAGA, 1998a).
O fungo se desenvolve em uma amplitude de temperatura compreendida entre 18 e $22^{\circ} \mathrm{C}$, com alta umidade relativa e presença de luz, na etapa de penetração e formação dos conídios. É favorecido por plantios adensados e pelo uso de nitrogênio em excesso, sendo que a planta mostra-se mais suscetível durante as fases de crescimento rápido (CRUZ FILHO; PINTO 1985; BERNHARDT et al., 1988; BEDENDO, 1995).

O controle do oídio baseia-se fundamentalmente no uso de produtos químicos envolvendo pulverizações com fungicidas específicos, bem como aqueles à base de enxofre, os quais podem provocar fitotoxidez, conforme dosagem, cultura e cultivar utilizada. O uso abusivo desses produtos tanto em relação ao emprego de altas doses, como em número excessivo de aplicações, tem aumentado a pressão de seleção e consequentemente o surgimento de indivíduos resistentes, além da contaminação do agroecossistema (ZAMBOLIM et al., 2000; FERNANDES, 2000). Apesar de a utilização de variedades resistentes ser uma das maneiras mais recomendadas, esta forma de controle não é totalmente eficiente para esta doença (BEDENDO, 1995).
O interesse pelos métodos alternativos de controle englobando os biológicos, orgânicos ou naturais é crescente (TRATCH; BETTIOL, 1997). Tais métodos apresentam algumas vantagens em relação aos produtos químicos como o baixo ou nenhum impacto ambiental, eficiência, custos reduzidos, simplicidade no manejo e aplicação. (PENTEADO, 1999; FERNANDES, 2000).

Bettiol et al. (1997) relataram o controle de oídio em pepino e abóbora com a utilização de metabólitos concentrados produzidos por Bacillus subtilis. Também em pepino, o controle de oídio com a utilização de sais orgânicos e inorgânicos, foi relatado por Reuveni et al. (1995) trabalhando em condições controladas.

O uso de diversos produtos alimentares e aditivos de alimentos (lecitina de soja, glutamatos, leite fermentado por Lactobacillus, bicarbonato de sódio, ácido tartárico, ácido fumárico, ácido sórbico, polifosfato de sódio, éster de açúcar, entre outros) vêm sendo pesquisados como alternativa viável para o controle de doenças de plantas, com resultados eficazes (MISATO et al., 1975; BETTIOL; ASTIARRAGA, 1998b). 
Bettiol e Astiarraga (1998b) avaliaram o produto lácteo obtido da fermentação do leite, com Lactobacillus (Yakult $^{\circledR}$ ) nas concentrações de 10 a $50 \%$ e aplicados uma e duas vezes por semana e obtiveram de 95 a $99 \%$, de controle do oídio da abobrinha. Esse mesmo produto quando utilizado na concentração de $10 \%$ e aplicado uma e duas vezes por semana, apresentou respectivamente, 75 e $91 \%$ de controle e a testemunha com fungicida $84 \%$. Eles também avaliaram resíduo de fermentação glutâmica do melaço comercializado como fertilizante, e a suspensão do resíduo contendo sais. Tanto o resíduo da fermentação glutâmica do melaço, como a suspensão do resíduo contendo sais foram eficazes, controlando a doença em 85 e $72 \%$, respectivamente.

Bettiol et al., (1999) trabalhando em condições controladas, utilizaram solução aquosa com leite de vaca cru, em concentrações de 5 a $50 \%$ para controle de oídio em abobrinha (Cucurbita pepo) e obtiveram de 95 a $99 \%$, respectivamente, de controle da doença.

Apesar de numerosos, a maioria dos trabalhos desenvolvidos nessa linha de pesquisa foram efetuados em condições controladas ou em laboratório e não tiveram comprovação de eficiência e aplicabilidade à campo. Este trabalho teve como objetivo avaliar, à campo, a eficiência de diferentes tipos de leite de vaca e sua associação ao leite fermentado por Lactobacillus (Yakult ${ }^{\circledR}$ ) industrialmente, no controle do oídio em abóbora, cultivar Piramoita.

\section{MATERIAL E MÉTODOS}

O trabalho foi desenvolvido na Fazenda Experimental São Manuel, FCA/ UNESP/Botucatu (SP), situada nas coordenadas geográficas de $22^{\circ} 46^{\prime} \mathrm{S}$ e $48^{\circ} 34^{\prime}$ W, numa altitude média de 740 metros. O clima é subtropical úmido, apresenta estiagens no período de inverno com temperatura e precipitação média anual de $21^{\circ} \mathrm{C}$ e $1534 \mathrm{~mm}$, respectivamente. O solo da área experimental é classificado como Latossolo Vermelho, textura franco arenosa.

A semeadura foi feita em 22/8/2001, utilizando-se bandejas de poliestireno expandido com 128 células e como substrato uma mistura de Plantmax, terra vegetal e casca de arroz carbonizada em proporções iguais, adubado com $3 \mathrm{~kg}$ da formulação 4-14-8 por $\mathrm{m}^{3}$ de substrato. Após a semeadura, as sementes foram cobertas com uma fina camada de casca de arroz carbonizada e as bandejas mantidas dentro da estufa plástica, tipo arco. A cultivar utilizada foi Piramoita e o transplante realizado em 05/9/2001, no espaçamento de $2,0 \times 1,5 \mathrm{~m}$, quando as plantas apresentavam 2 a 3 folhas definitivas.

$\mathrm{Na}$ adubação de plantio utilizou-se $5 \mathrm{~L}$ de composto e 150 gramas da fórmula 4-14-8 por $\mathrm{m}^{2}$ que, após a distribuição a lanço, foram incorporados com rotoencanteirador. Após o transplante foi colocada, como cobertura morta, uma camada fina de acícula de pinus ao redor das plantas, num raio aproximado de $0,50 \mathrm{~m}$. A irrigação por aspersão foi aplicada sempre que necessária, bem como as capinas.

Foram avaliados os tratamentos: 1) água, como controle; 2) leite cru; 3) leite pasteurizado do tipo $\mathrm{C}$; 4) leite integral do tipo longa vida (UHT); 5) leite pasteurizado do tipo $\mathrm{C}+$ produto lácteo obtido da fermentação do leite por Lactobacilus (produto comercial Yakult $^{\circledR}$,Yakult ${ }^{\circledR}$ S.A. Ind. e Com.); 6) leite integral do tipo longa vida (UHT) + Yakult $^{\circledR}$. Os tipos de leite e o Yakult ${ }^{\circledR}$ foram utilizados nas concentrações de $20 \%$ e $2 \%$, respectivamente, e aplicados duas vezes por semana, sendo o Yakult $^{\circledast}$ agitado antes de ser adicionado à solução. $\mathrm{O}$ delineamento experimental foi de blocos ao acaso com cinco repetições e cinco plantas por parcela. A primeira aplicação dos tratamentos ocorreu 48 dias após o transplante, quando foi observada distribuição uniforme do patógeno, na face abaxial das folhas, em todas as plantas, cujo inóculo teve ocorrência natural. Na ocasião, cerca de $20 \%$ das plantas apresentavam-se no início do florescimento. As aplicações foram feitas utilizando pulverizador costal de acionamento manual, com capacidade para 5 L, a uma vazão de 300 L/ha. As soluções foram preparadas no momento de cada aplicação, sempre no período da manhã.

Para quantificação da doença estimou-se a área foliar afetada, utilizando-se escala diagramática de severida- de proposta por Azevedo e Leite (1996): $1=$ plantas sem sintomas, $2=$ plantas apresentando até $10 \%$ da área foliar com sintomas, $3=$ plantas com 10 a 15\% da área foliar com sintomas, 4=plantas com 15 a $25 \%$ da área foliar com sintomas, 5=plantas com 25 a $40 \%$ da área foliar com sintomas; $6=$ plantas com até $50 \%$ da área foliar com sintomas. Antes da primeira aplicação dos tratamentos foi feita avaliação inicial da severidade da doença em todas as plantas, que se repetiu semanalmente, num total de cinco avaliações, feitas por um único avaliador. Comparou-se as médias do tratamento pelo teste de Tukey (5\%) e pela integralização da doença no tempo, através da área sob a curva de progresso da doença (ASCPD) (BERGER, 1988).

\section{RESULTADOS E DISCUSSÃO}

As médias da primeira avaliação (Tabela 1) revelam que não houve diferença entre os tratamentos, o que demonstrou que a distribuição do patógeno foi uniforme, na face abaxial das folhas, em todas as parcelas da área experimental, de forma natural, no início da aplicação dos tratamentos, cuja média da área foliar afetada foi de $11,6 \%$. Na segunda avaliação (Tabela 1) os tratamento com leite cru e com leite do tipo C diferiram da testemunha, que apresentou maior severidade média da doença $(15,4 \%)$ enquanto o leite cru proporcionou a menor área foliar afetada média $(11,4 \%)$. A partir da terceira avaliação (Tabela 1) a testemunha apresentou maior severidade da doença, diferindo de todos os outros tratamentos. Constatou-se, em todas as plantas da testemunha, um avançado ataque da doença com senescência das folhas, as quais se apresentavam com coloração amarelada para marrom e o secamento dos ponteiros das plantas, em decorrência do ataque do patógeno. De acordo com a descrição de Bedendo (1995) esse efeito se deve à interferência do fungo no processo fotossintético da planta, retirada de nutrientes das células e diminuição da quantidade de luz que chega à superfície das folhas. Na tabela 1 observa-se a severidade da doença, expressa em percentagem de área lesionada média, nos diferentes tratamentos, mesmo com a utili- 
Tabela 1. Médias da \% de área foliar afetada com oídio em avaliações semanais feitas para quantificação da doença em abóbora cv. Piramoita. São Manuel, SP, UNESP, 2001.

\begin{tabular}{|c|c|c|c|c|c|c|}
\hline \multirow{2}{*}{ Tratamento } & \multicolumn{6}{|c|}{ Avaliações (\%) } \\
\hline & $1^{a}$ & $2^{a}$ & $3^{a}$ & $4^{a}$ & $5^{a}$ & ASCPD** \\
\hline Controle & $11,8 \mathrm{a}$ & $15,4 \mathrm{a}$ & $33,7 \mathrm{a}$ & $45,2 \mathrm{a}$ & $55,0 \mathrm{a}$ & 718,9 a \\
\hline Leite cru & $11,2 \mathrm{a}$ & $11,4 \mathrm{c}$ & $11,4 b$ & $11,0 \mathrm{~d}$ & $11,2 \mathrm{c}$ & $287,0 \mathrm{c}$ \\
\hline Leite tipo C & 11,6 a & $12,0 \mathrm{bc}$ & $12,8 b$ & $14,2 \mathrm{~cd}$ & $15,6 \mathrm{bc}$ & $331,1 \mathrm{bc}$ \\
\hline Leite longa vida & 11,6 a & $14,0 \mathrm{abc}$ & $16,2 \mathrm{~b}$ & $21,2 b$ & $20,7 b$ & $427,5 \mathrm{~b}$ \\
\hline Leite tipo C + Yakult & $11,2 \mathrm{a}$ & $13,8 a b c$ & $14,6 \mathrm{~b}$ & $15,2 \mathrm{c}$ & $15,6 \mathrm{bc}$ & $375,7 \mathrm{bc}$ \\
\hline Leite longa vida + Yakult & $13,2 \mathrm{a}$ & $14,6 \mathrm{ab}$ & $14,8 \mathrm{~b}$ & $16,8 \mathrm{c}$ & $18,0 \mathrm{bc}$ & $399,4 \mathrm{bc}$ \\
\hline $\mathrm{CV}(\%)$ & 13,95 & 11,36 & 14,23 & 9,03 & 16,32 & 15,83 \\
\hline
\end{tabular}

Médias, dentro da coluna, seguidas pela mesma letra não diferem, pelo teste de Tukey a $5 \%$.

*Avaliação antes da aplicação dos tratamentos com leite.

**(ASCPD) Área sob a curva de progresso da doença

zação da irrigação por aspersão que é o menos favorável a evolução desta doença, em abóbora (COELHO, et al., 2000).

No tratamento com leite cru, o valor médio da área foliar afetada permaneceu praticamente estável (11,0 a 11,4\%) durante toda fase experimental (Tabela 1) o que revela o efeito desse tipo de leite no controle do patógeno. O leite cru e fresco possui na sua composição diversos constituintes, entre eles sais de $\mathrm{Ca}$, Fosfato, Fe, Mg, proteínas, vitaminas, aminoácidos, gorduras, microorganismos e outros, em concentrações diferenciadas dos demais tipos de leite (HAMAN; KRÖMKER, 1997). Assim, ele pode ter mais de um modo de ação sobre o fungo, até um efeito direto contra $S$. fuliginea devido aos seus componentes e ou a presença de microorganismos não presentes nos leites pasteurizados, principalmente no longa vida. (BETTIOL et al., 1999). Bettiol e Astiarraga (1998a) avaliaram a eficiência do leite de vaca cru nas concentrações $5 ; 10 ; 20 ; 30 ; 40$ e 50\% para o controle do oídio em abobrinha, em condiçõos controladas. As maiores concentrações foram as mais eficazes no controle da doença, entretanto, foi em concentrações acima de $10 \%$ que o leite controlou a doença. No tratamento com leite tipo C (Tabela 1) observou-se uma variação de 11,6\% a 15,6\% da área foliar afetada média, sinalizando maior severidade da doença, se comparada ao leite cru. Contudo, apresentou maior eficiência, no controle da doença, quando comparado aos demais tratamentos. Esse resultado provavelmente se deve às características desse leite devido ao processo de industrialização, que pode modificar ou alterar menos a composição, concentração das substâncias e dos microorganismos fermentadores, dos sais entre outros, em relação ao leite longa vida. Bettiol et al. (1999) descrevem que o leite cru pode ter diversas maneiras de ação no controle do oídio em abobrinha, como um efeito direto sobre $S$. fuliginea, devido aos microorganismos, sais e ácidos. Estas substâncias têm sido relatadas como efetivas no controle desta e de outras doenças (MISATO et al, 1975). Além disso o leite pode também, indiretamente, afetar o $S$. fuliginea induzindo o sistema de resistência (BETTIOL et al., 1999).

No tratamento com leite do tipo longa vida, a variação da área foliar afetada média foi de 11,6 a 21,2\%, diferindo do controle na terceira, quarta e quinta avaliações, mas apresentaram controle inferior ao tratamento com leite cru, nas duas últimas e do tratamento com leite do tipo $\mathrm{C}$ na quarta avaliação (Tabela 1). Sugere-se para esse tipo de leite, que as modificações biológicas, durante o processo industrial, possam afetar a sua eficiência se comparada ao leite cru.

Os dois tratamentos associados ao leite fermentado por Lactobacilus vivos, leite tipo $\mathrm{C}+$ Yakult $^{\circledR}$ e leite tipo longa vida + Yakult $^{\circledR}$ (Tabela 1) diferiram do controle na terceira, quarta e quinta avaliações. Esses tratamentos foram mais eficientes que o tratamento do leite tipo longa vida na quarta avaliação, porém apresentaram resultados semelhantes entre si e inferiores ao leite cru.

A área sob a curva do progresso da doença (ASCPD) (Tabela 1) expressa a doença durante todo o período experimental e reforça os dados obtidos na quinta avaliação, onde houve diferença significativa entre a testemunha e os demais tratamentos. Concluiu-se que o leite é uma alternativa viável no controle do oídio, mesmo após o início da infecção, no campo, sendo que sua utilização na forma de leite cru é mais eficiente e na forma de longa vida o menos eficiente.

\section{LITERATURA CITADA}

AZEVEDO, L.A.S.; LEITE, O.M.C. Manual de quantificação de doenças de plantas. São Paulo: Ciba Agro, 1996. 73 p.

BEDENDO, I.P. Oídios. In: BERGAMIN FILHO, A.; KIMATI, H.; AMORIM, L. Manual de fitopatologia, 3. ed. São Paulo: Ceres, 1995. v.1, p.866-871

BERGER, P.D. The analysis of effects of control measures on the development of epidemics. In: KRANZ, J.; ROTEM, J. Experimental techniques in plant disease epidemiology. Heideberg: Springer-Verlag, 1988. p.137-151.

BERNHARDT, E.; DODSON, J.; WATTERSON, J. Cucurbit diseases: a practical guide for seedsmen, growers \& agricultural advisors. Califórnia: Petoseed Co. 1988. 48 p.

BETTIOL, W.; ASTIARRAGA, B.D. Possibilidades de controle de oídio (Sphaerotheca fuliginea) da abobrinha com leite cru. Pesquisa em Andamento, Centro Nacional de Pesquisa de Monitoramento e Avaliação de Impacto Ambiental, Embrapa, Jaguariúna, n.3, maio, p.17. 1998a.

BETTIOL, W.; ASTIARRAGA, B.D. Controle de Sphaerotheca fuliginea em abobrinha com resíduo da fermentação glutâmica do melaço e produto lácteo fermentado. Fitopatologia Brasileira, Brasília, v.23, n.4, p.431-435, 1998 b.

BETTIOL, W.; ASTIARRAGA, B.D.; LUIZ, A.J.B. Efectiveness of cow's milk against zucchini squash powdery mildew (Sphaerotheca fuliginea) in greenhouse conditions. Crop Protection, Guildford, v.18, n.8, p.489-492, 1999. 
BETTIOL, W.; GARIBALDI, A.; MIGHELI, Q. Bacillus subtilis for the control of powdery mildew on cucumer and zucchini squash. Bragantia, Campinas, v.2, n.56 p.281-287, 1997.

BETTIOL, W.; TRATCH, R.; GALVÃO, J.A.H Controle de doenças de plantas com biofertilizantes. Circular Técnica, Centro Nacional de Pesquisa do Meio Ambiente. Embrapa, Jaguariúna, n.2, p.1-22, 1997.

COELHO, M.V.S.; CAFÉ FILHO, A.C.; LOPES C.A.; MARROUELLI, W.A. Severidade de oídio em abóbora híbrida sob diferentes lâminas de irrigação e níveis de nitrogênio. Fitopatologia Brasileira, Brasília, v.25, n.2, p.157-160, 2000.

CRUZ FILHO, J.; PINTO, C.M.F. Doenças das cucurbitáceas induzidas por fungos e bactérias. Informe Agropecuário, Belo Horizonte, n.85, p.3851, 1982.

FERNANDES, M.C.A. Emprego de métodos alternativos de controle de pragas e doenças na olericultura. Horticultura Brasileira, Brasília, v.18, Suplemento, p.112-113, 2000.
HAMANN, J.; KRÖMKER, V. Potencial of specific milk composition variables for cow health management. Livestock Production Science, v.48 n.1, p.201-208, 1997.

KIMATI, H.; CARDOSO, C.O.M.; BERGAMIN

FILHO, A. Doenças das cucurbitáceas (abóbora abobrinha, chuchu, melancia, melão, moranga, pepino). In: GALLI, F. Manual de fitopatologia: doenças das plantas cultivadas. São Paulo: Ceres, 1980. p.251-269.

KUROZAWA, C.; PAVAN, M.A. Doenças das cucurbitáceas. (abóbora, abobrinha, chuchu, melancia, melão, moranga, pepino). In: KIMATI, H.; AMORIM, L.; BERGAMIN FILHO, O.A.; CAMARGO, L.E.A.; REZENDE, J.A.M. Мапиal de fitopatologia. 3. ed. São Paulo: Ceres, 1997. v.2, p.325-337.

MISATO, T.; WAKAMATSU, H.; NATSUME, T.; YOSHIOKA, A.; KISHI, K. Utilization of additives as agricultural fungicides. Annals Phytopathological Society of Japan, v.41, n.1, p.73-76, 1975.
PENTEADO, S.R. Defensivos alternativos e naturais: para uma agricultura saudável. Campinas: sn, 1999. 79 p.

REUVENI, M.; AGAPOV, V.; REUVENI, R. Suppression of cucumber powdery mildew (Sphaerotheca fuliginea) by foliar sprays of phosphate and potassium salts. Plant Pathology, Cambridge, v.44, n.1, p.31-39, 1995.

TRATCH, R.; BETTIOL, W. Efeito de biofertilizantes sobre o crescimento micelial e a germinação de esporos de alguns fungos patogênicos. Pesquisa Agropecuária Brasileira, Brasília, v.32, n.11, p.1131-1139, 1997.

ZAMBOLIM, L.; COSTA, H.; VALE, F.X.R. Situação atual do controle químico de doenças de hortaliças. Horticultura Brasileira, Brasília, v.18, Suplemento, p.96-110, 2000.

ZIV, O.; ZITTER, T.A. Effects of bicarbonates and film-formingpolymers on cucurbit foliar diseases. Plant Disease, v.76, n.5, p.513-517, 1992. 